\title{
Social Development with Public Value: An International Comparison
}

\author{
Bing Wang ${ }^{1}$ (D) $\cdot$ Longmei Xia $^{1} \cdot$ Alfred M. Wu $^{2}$
}

Accepted: 19 April 2021 / Published online: 1 January 2022

(c) The Author(s) 2021

\begin{abstract}
Social development around the world has been stunted by the lack of a comprehensive understanding and definition of public value. Public value theory can provide guidance, and inform a universal standard for social development. However, it is difficult to define and measure public value due to its philosophical complexity. Public values are driven by various economic, political, and social forces, and can be created by many stakeholders including enterprises, governments and non-governmental organisations. Government is central to human society and is primarily responsible for inclusive social development, which requires setting and maintaining public values orderly and synchronously according to the plurality of views held by those in society. Social development failure may occur when some key public values are ignored. This study uses thirty economic, social, and political indicators to measure public value, and the results demonstrate strong correlations among them. Through a principal component analysis and a cluster analysis, these thirty indicators can be reduced to four principal components. The first one, which represents economic value, can explain $65.8 \%$ of the total information, identifying that economic value is playing a fundamental role among plural public values. Countries are clustered and their development neighbors are identified in order to compare countries with similar levels of development. Public value theory can help to understand the advantages and disadvantages of different countries, and advance the social and economic progress steadily and authentically.
\end{abstract}

Keywords Public value $\cdot$ Measurement $\cdot$ Social development $\cdot$ Indicator $\cdot$ Principal component analysis $\cdot$ Cluster analysis

Bing Wang

wbyf@hust.edu.cn

Longmei Xia

44585707@qq.com

Alfred M. Wu

alfredwu@nus.edu.sg

1 College of Public Administration, Huazhong University of Science and Technology (HUST), Wuhan 430074, Hubei Province, People's Republic of China

2 Lee Kuan Yew School of Public Policy, National University of Singapore, Singapore 259772, Singapore 


\section{Introduction}

Against the background of a global market society, "creating value" has become a slogan of corporations and entrepreneurs. However, value cannot be created solely by the private sector, without the involvement of government or non-governmental-organization (NGO). As companies are profit-driven, economic value is prioritized over other kinds of social value. The rise of New Public Management (NPM) in the 1980s inspired managerialism, market-oriented public administration, and quasi-market administration (Borins, 1995; Dunleavy \& Hood, 1994; Manning, 2001; Osborne \& Gaebler, 1992; Overeem \& Tholen, 2011). ${ }^{1}$ This tendency led to a greater integration of public institutions and the private sector, allowing for the creation of new values. However, human society does not become better comprehensively because of critical social problems such as inequality, terrorism, populism, ecological crisis and climate change. Government and public sector can also create public values (Moore, 1995), some are cherished by the general public and the entire society, including truth, goodness, beauty, freedom, justice, responsibility, innovation, etc. These values cannot necessarily be measured in a monetary unit, and are the foundation of social development (Elkington, 1999; Scherer et al., 2016; Sheehy, 2015).

However, public value is still a controversial concept and is difficult to define and measure. It contains many related and intersecting concepts such as intrinsic value, extrinsic value, universal value, subjective value, objective value, private value, public value, etc. From a philosophical perspective, Zimmerman (2014) believed that value traditionally lied at the heart of ethics. Rokeach $(1973$, p. 3) asserted that: "The value concept, more than any other, should occupy a central position ... able to unify the apparently diverse interests of all the sciences concerned with human behavior". The World Values Survey (WVS), introduced in 1981, claimed that values change the world and offered an understanding of national political, social, and economic values that can be compared across contexts (Inglehart, 2008; Won, 2013). As an extension of these value concepts to the public sector, public value theory has been viewed as "a big thing" (Talbot, 2009), a "paradigmatic change" (O'Flynn, 2007), and "beyond traditional public administration and the new public management" (Bryson et al., 2014). However, without a clarification of value concept, the arguments of public value have been trapped in rhetorical controversies and unable to effectively guide government policies and human behaviors (Beck Jørgensen \& Bozeman, 2007; Bozeman \& Johnson, 2015; Faulkner \& Kaufman, 2017; Moore, 2014).

Government is an important part of society and responsible for advancing social development through its policies. The success and failure of any country can be attributed to the quality of governance practiced by the government. "In the absence of valid theory, social development remains largely a process of trial-and- error with a high failure rate and uneven progress" (Jacobs \& Cleveland, 1999; Wang \& Christensen, 2017, p. 855), considering those various social problems such as inequality, unemployment, crime, terrorism, environmental degradation and climate change. Only a few countries have achieved steady social development in the past several decades, while most others have experienced various development failures. The notable examples include the collapse of the Former Soviet

\footnotetext{
1 New Public Management was a worldwide movement in the 1980s when most governments implemented market-oriented reforms to enhance economic growth and efficiency. Notable examples included the Margaret Thatcher government in the UK and the Ronald Reagan administration the US. These movements have pushed the economic growth but enlarged the social inequality, with the profound influences and consequences till now.
} 
Union (FSU), the middle-income trap in Latin America, the long-term poverty in Africa, and the recent rise of populism in the E.U. and the U.S. (Brubaker, 2017; Fukuyama, 2014; Ikenberry, 2017).

Social development implicitly means becoming "better". Without a concrete definition of what constitutes the value of goodness, it is imprecise to claim all human history as social development, but rather as a continuum of social change and transformation. If a country is achieving more economic success but witnessing a deterioration in democracy, social justice, or environment, it is unreasonable to claim this process as social development. Crisis and failure in the future may occur. Social development, as well as sustainable and inclusive development, should be the synchronous and orderly enhancement of public values in key social spheres. ${ }^{2}$ The theory of public value can offer human society clear directions, help humankind understand the complex relationships among diverse values, and diagnose potential crises. Ultimately, a clear and universal understanding of public value has the potential to make our countries and societies better (Wang, 2016; Wang \& Christensen, 2017).

The competitiveness of countries is based upon their capacity and capability to create public values. Rising China has become a rival to the U.S. in every major arena (Allison, 2017; Jacques, 2012; Kissinger, 2014). During the Cold War, the U.S. and the Soviet Union were similarly positioned, but the latter ultimately collapsed because its government failed to create public values such as economic wealth, political freedom, and cultural diversity (Marples, 2004; Sherman, 2016). Military power alone is unable to sustain a country's position as a hegemon. Currently, as the second-largest economy and the world's manufacturing hub, China has created a great amount of economic and related values. ${ }^{3}$ However, if it cannot create other political values such as democracy, freedom, the rule of law, and social values such as environmental protection and happiness, its development in the future will be uneven (Shambaugh, 2016). In contrast, as the world's largest democratic country, India has created more freedom and democracy but faced worse economic conditions than China (Cooper \& Farooq, 2015; Loubser \& Steenekamp, 2017; Rana, 2017; Wang, 2011). Public value theory can explain and illuminate the strengths and weaknesses of China, India, the U.S., and other countries around the world.

This article aims to contribute to theory and practice in three ways. Firstly, it will compare various value concepts and clarify related public values. Secondly, this article will identify the public value foundation of existing economic, political, and social indicators and present the various indices to measure related public values. Thirdly, in order to explore the sophisticated relationships among indices and plural public values, we collect 30 influential and reliable indicators and apply the correlation analysis, principal component analysis (PCA) and cluster analysis. We find that economic value is the first principal component and can explain $65.8 \%$ of information of these indicators, and accordingly,

\footnotetext{
${ }^{2}$ Synchronicity requires that all values should increase, at least not decrease, during a period. Orderliness requires that all the values should increase according to the careful arrangement of governments. Synchronicity is a stricter requirement than orderliness.

3 In 1980, China's GDP in nominal value ranked no. 12 in the world, behind Brazil (no. 8), Spain (no. 9), Mexico (no. 10), Netherland (no. 11), and was only $6.7 \%$ of the US. Its GDP per capita in nominal value was \$194, at the bottom four among 149 economies, just a little higher than Somalia (\$96), Uganda (\$100), Nepal (\$129), and Guinea-Bissau (\$141). In 2018, China’s GDP in nominal value was no. 2 in the world, $66.9 \%$ of the US. And its GDP per capita was \$10,261, ranking no. 68 among the 184 economies (World Bank, 2020). China's rank on Human Development Index has improved from no. 103 in 1990 to no. 85 in 2018 (UNDP, 2020).
} 
countries can be clustered and ranked. Finally, the article concludes with a summary and future outlook.

\section{Public Values and Social Development}

As a philosophical concept, public value is controversial and highly debated. Four basic questions have been presented by Beck Jørgensen and Bozeman (2007): "What is the origin of public values? Is there a hierarchy of public values? What are the possibilities for assessing public values? (4) How do public values fit together?" (Wang, 2016, p. 135) These questions can be clearly answered by clarifying the various concepts of value in philosophy.

\subsection{Intrinsic Value and Extrinsic Value}

Public value is associated with intrinsic value. Truth, goodness, and beauty are the basic objects of philosophy and the ultimate goals of human society. All these objects are intrinsic values, which means that the values are ultimate and not dependent upon other values. In contrast, extrinsic values are instrumental and dependent upon other values (Zimmerman, 2014). Pleasure and happiness are the most common intrinsic values, as they are the basis of material wealth, GDP, and economic well-being. Other typical public values such as democracy and freedom can also be considered as intrinsic values.

The argument of intrinsic and extrinsic value is not only philosophical but also pragmatic. The ecological and climate crises have inspired scholars to question whether the natural environment has some intrinsic value irrelevant of its usefulness to humankind (Attfield, 1998; Butler \& Acott, 2007). If the environment has only extrinsic or instrumental value depending only on the needs of humans, humankind has valid reasons to exploit the environment for their selfish benefit. A fundamental solution to the ecological and climate crisis requires a basic change of value from shallow to deep ecology, which entails entitling the environment and ecology some intrinsic values independent of human's instrumental or extrinsic evaluations (Booth, 2013; Kopnina \& Cherniak, 2015; Næss, 1973).

\subsection{Human Value and Universal Value}

Intrinsic value may lead to the danger of absolutism and autocracy because intrinsic value cannot be questioned and doubted (Harris, 2010). However, human value and universal value may not be as absolute as intrinsic ones. Democracy, freedom, and happiness can be reasonably understood as human and universal values. The Tanner Lectures on Human Values are a series of lectures delivered by outstanding scholars in reputable universities annually, which clarify the meaning and significance of human values such as freedom, liberty, democracy, equality, and human rights. ${ }^{4}$ The human values argued in these lectures

\footnotetext{
4 These universities are Oxford University, Cambridge University, Harvard University, Princeton University, Stanford University, University of California, Berkeley, University of Michigan, University of Utah, Yale University, and other educational institutions around the world. The lecturers and topics can be found on http://tannerlectures.utah.edu/lectures/index.html.
} 
can help human society understand the meaning and significance of humanity and direct people to make the world a better place.

Similar to human value, the universal value is the value shared and pursued by all of humankind. Particularly, the Outstanding Universal Value is the basis of UNESCO's World Heritage. It is the Outstanding Universal Value of those heritages, but not the economic profit or temporary well-being that is worthy of protection. The human values and universal values are not only philosophical arguments but substantially and pragmatically protected by human behaviors and government policies (Hazen, 2008; Rojas, 2015; Zorba, 2009).

\subsection{Objective Value and Subjective Value}

A value can be objective or subjective. Plato argued in favor of the objectivity of values such as truth, goodness, and beauty, as he believed that these values are inherently consistent, absolute, intrinsic, objective, and existent in the universe, waiting to be discovered and recognized by humans. However, this idea is also viewed as moral absolutism and a possible bridge to totalitarianism (Hawley, 2008; Popper, 1972; Sagar, 2015).

Even if a value is objective and intrinsic, it still requires the recognition, appreciation, and acceptance by humans. This means that all the values should be subjectively perceived and recognized by humans. Therefore, the subjective well-being (SWB) and other related entities such as happiness and life satisfaction, generally surveyed by Pew and Gallup, are essentially various subjective values (Inglehart, 2008; Rokeach, 1973; Schwartz, 1994; Schwartz \& Boehnke, 2004). This means that all the values, including democracy, freedom, and happiness, are subjective and can be measured and quantified by the questionnaire.

\subsection{Monistic Value and Plural Value}

There are great controversies in philosophy between value monism and value pluralism. Value monism has been advocated and defended by some great philosophers, such as Plato, Spinoza, and Hegel (Moen, 2016; Schaffer, 2014). However, it has few advocates in modern capitalist societies because of the obvious conflicting plural values (Sidorsky, 2013). Similar to Beck Jørgensen and Bozeman's (2007) public values inventory, which contains 66 value items, Frankena (1973) suggested a most comprehensive list of values, including life, health, happiness, equity, freedom, justice. However, the relationships among these plural values are complex and controversial.

Value pluralism will lead to value conflicts in practice and policy. Some of the plural values are consistent, such as freedom and democracy, peace and security, innovation and novelty, while others may be conflicting, such as efficiency and equality, innovation and stability, tradition and modernity, etc. Economics is based upon value monism, and the economic value conflict can be solved by value maximization and Pareto optimization. In contrast, ethics is based upon value pluralism, and the plural value conflicts of culture, religion, and morality are difficult to be harmonized (de Graaf et al., 2016; Oldenhof et al., 2014; Thacher \& Rein, 2004). Value deliberation can be the possible solution, requiring value holders to understand and appreciate different values. The deliberative democracy is the deliberation among different value holders, while the traditional representative democracy is based upon the majority rule. This is the possible reason driving the current crisis 
of representative democracy (Berg \& Lidskog, 2018; Dryzek, 2019; Fishkin, 2018; Goodin, 2017).

\subsection{Private Value and Public Value}

Values are dispersed throughout all human spheres and can be categorized into public and private. Private values can be understood as values possessed by a small group of people who always adhere to traditions. They may behave in a way that is considered uncommon to most people, but that reflects their own specific values. Their values are private initially, but gradually some of them may spread to society and be accepted by most people and thus become public. This demonstrates that values evolve over time, and the theoretical debates can clarify these fuzzy values to help people understand them. Governments can make appropriate policies to protect and create these values.

Human society can be trichotomized into three spheres: economic, political, and social. Accordingly, public values can be classified into economic, political, and social values. Corporations and entrepreneurs can create economic values through their entrepreneurship. Similarly, governments and politicians can create political values; and NGOs and social activists can create social values. Value creation is actually the mission of these organizations. Since all these organizational leaders must utilize their wisdom and techniques to overcome difficulties and create different types of values, governments and politicians can also be regarded as political enterprises and political entrepreneurs, and NGOs and social activists as social enterprises and social entrepreneurs (Campbell \& Witcher, 2015; Kosack, 2014).

There is a hierarchy or priority of public values, and public values may fit or conflict with each other. In alignment with Maslow's (1943) Hierarchy of Needs, values such as life, health, and wealth are fundamental, while others are higher as a second order, such as democracy, freedom, and environmental protection, although different people may have different evaluations and prioritization. Generally, only after governments satisfy people's demands for basic public values will they pursue those higher ones. This means that governments need to properly arrange the order of public values and development in different social spheres. Economic and social entrepreneurs can pursue their relative monistic values such as profits and human rights, while politicians and governments must balance and compromise plural public values. Therefore, politicians will always confront much more intractable value conflicts than their economic and social counterparts. If politicians and governments wrongly prioritize public values, or ignore some crucial ones, their countries will be at risk, and development failure may occur.

\subsection{Social Development and the Indicators}

Social development implicitly means that human society is becoming better. Yet without a clear definition of the values that contribute to social progress, it is imprecise to claim human history as social development, but rather as neutral social change or transformation (Wang \& Christensen, 2017). Human society has generated substantial amounts of economic wealth and scientific knowledge, but social equality, justice, sustainability, and happiness have decreased (Piketty, 2017). Due to value monism, the monistic economic growth has been confused as the plural social development, and economics has gained the reputation of "knowing the price of everything but the value of nothing" (Ackerman \& Heinzerling, 2005; Anderson, 1993). 
Public value and social development can be measured by political, economic, and social indicators. For example, the Human Development Index (HDI) compiled by the United Nations Development Programme (UNDP) has three components: the ability to lead a long and healthy life, measured by life expectancy (LIF) at birth; the ability to acquire knowledge, measured by mean years of schooling (MYS) and expected years of schooling (EYS); and the ability to achieve a decent standard of living, measured by gross national income (GNI) per capita. These components are based upon the public values of economy, health, and knowledge, but the HDI does not include equity and environment, and so is not comprehensive as its title implies. The UNDP began to calculate the inequality-adjusted HDI after 2015, and may further compile the environment-adjusted HDI. Similarly, the Inclusive Wealth Index (IWI), compiled by the United Nations Environment Programme (UNEP, 2018), aims to measure sustainability and well-being of countries and the world. It encompasses three components: natural capital, produced capital, and human capital, with their implicit public values.

Another relatively new Inclusive Development Index (IDI), compiled by the World Economic Forum (WEF), is more comprehensive with seven pillars: (1) education and skill; (2) basic services and infrastructure; (3) corruption and rents; (4) financial intermediation of real economy investment; (5) asset building and entrepreneurship; (6) employment and labor compensation; and (7) fiscal transfers. However, when compiling the Economic Freedom Index, Gwartneya and Lawson (2003, p. 419) noted "we struggled with how the components should be aggregated into area and summary ratings" and "none of these alternative methods is completely satisfactory". The satisfactory measurement and indexation can be achieved after the clarification of the relationship of their potential public values.

\section{Data and Methodology}

As noted above, human society can be roughly trichotomized into economic, political and social realms, and social development should be comprehensive and balanced within all these spheres (Wang \& Christensen, 2017). These spheres can be measured by economic, political, and social indicators. Nearly all of them have explicit or implicit public value foundations, such as GDP per capita, Global Competitiveness Index, and HDI. The sophisticated relationships among various public values can be discovered by the related indicators and the methodologies of correlation analysis, principal component analysis, and cluster analysis. By utilizing the data, our research can be verified, replicated, and expanded.

\subsection{Data}

Table 1 lists three categories of public values and their possible indicators. These indicators are compiled and released by influential organizations, such as the World Bank (W.B.), the U.N., the World Economic Forum (WEF), Transparency International (T.I.), Yale University, and Columbia University. Thus, their reliability can be guaranteed. Similar indicators have been selected for crosschecking the results, including nominal GDP per capita (GDPC), real GDP per capita based on purchasing power parity (GDPR), real GNI per capita (GNIR), electricity consumption per capita (ELE). Most indicators are recent as of 2017-2018, but not for the exact same year because of time lags. This does not weaken the analysis because these indicators do not change dramatically. 


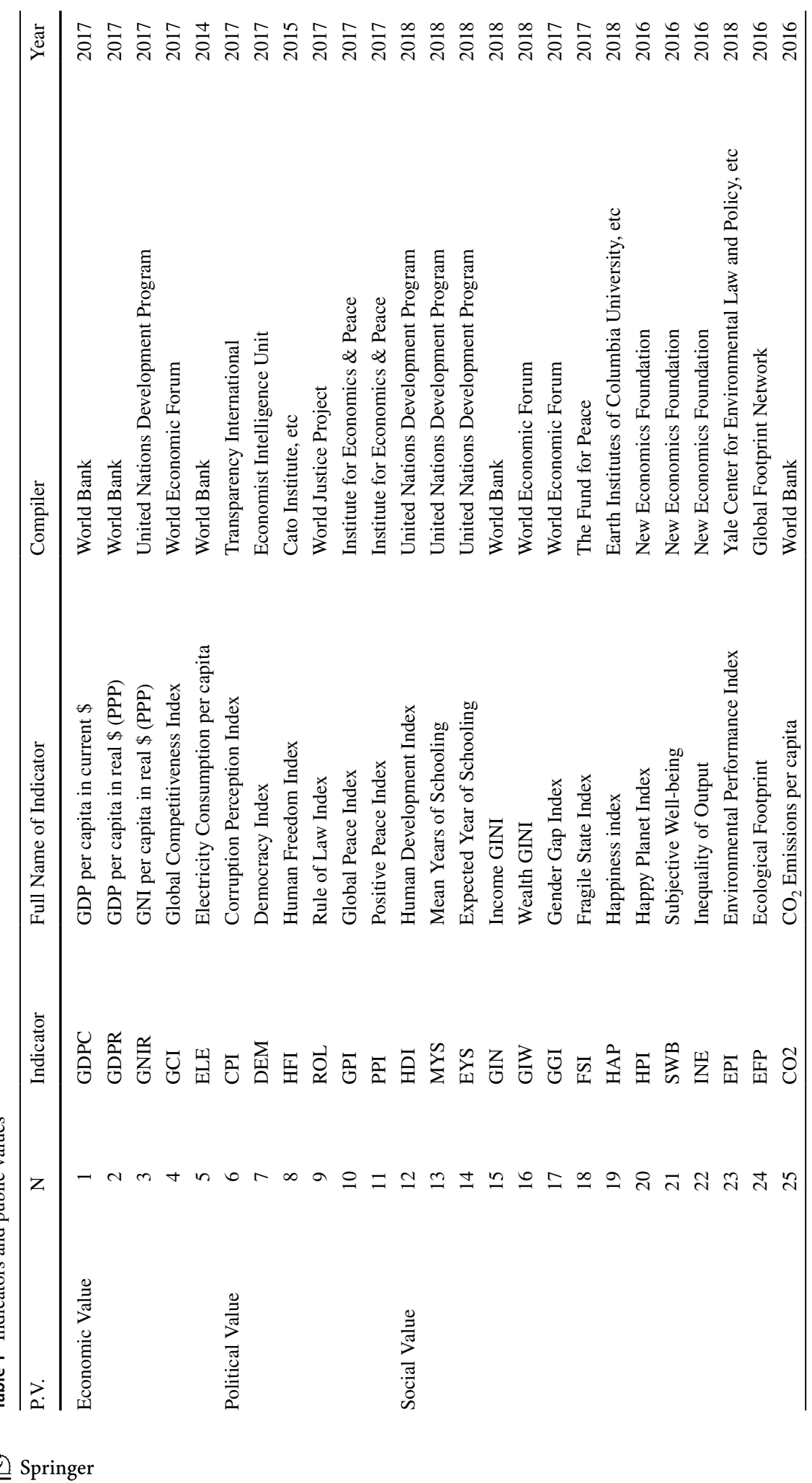




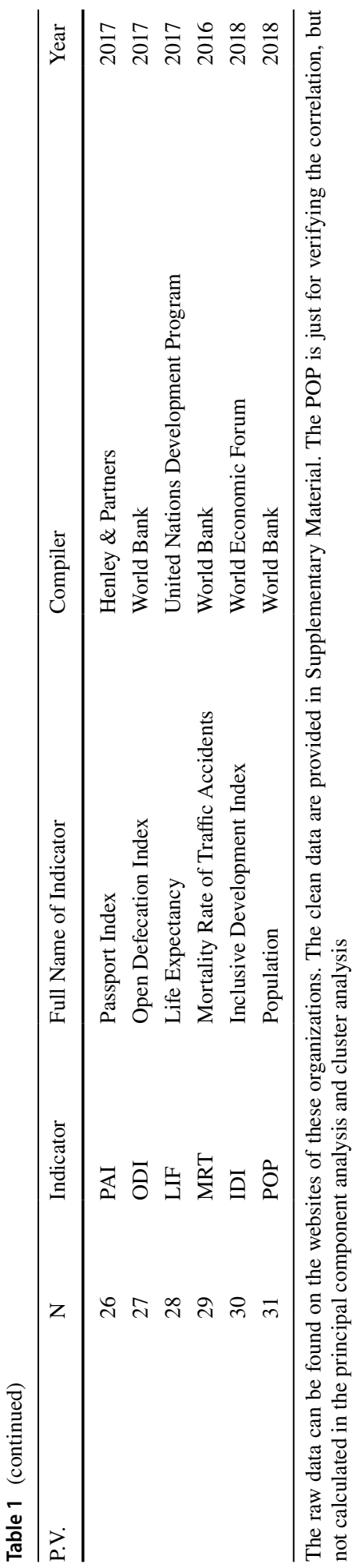


The economic value can be partially measured by GDP per capita, The Global Competitiveness Index (GCI) and Electricity Consumption per capita (ELE). The GCI is composed of three sub-indexes: (1) basic requirements, (2) efficiency enhancers, (3) innovation and sophistication factors (Schwab, 2012). These sub-indexes are based upon efficiency as economic value, institution as political value, and education as social value. The ELE can represent infrastructures, and it is reasonable to predict that economic value will statistically enhance all infrastructures including not only ELE but also transportation, water, information and communication technology, etc. We can reasonably anticipate that these indicators are strongly correlated and are the foundation of other public values.

The political value can be partially measured by the Corruption Perception Index (CPI), Democracy Index (DEM), Human Freedom Index (HFI), Rule of Law (ROL), Global Peace Index (GPI), Positive Peace Index (PPI). These indicators have their own specific values but also overlap to some extent. For example, the CPI is the average of 13 data sources, including the World Bank's Country Policy and Institutional Assessment, the WEF Executive Opinion Survey, the World Justice Project Rule of Law Index, etc. It includes interviews with business executives and experts on corruption behaviors in the public sector, with a full score of 100. The DEM is composed of five dimensions: (1) electoral process and pluralism, (2) functioning of government, (3) political participation, (4) political culture, and (5) civil liberties, subjectively assessed by experts with the full score of 10 . The HFI is composed of personal freedom and economic freedom. The former includes the rule of law, security and safety, movement, religious freedom, association, expression and information, identity and relationships. The latter includes size of government, legal system and property rights, sound money, freedom to trade internationally, regulation, with a full score of 10 . We can reasonably predict that these political value indicators will enhance each other and correlate with economic value indicators.

Social value is more diverse than economic and political values. The Fragile State Index (FSI) includes four subgroups of indicators, cohesion, economic, political and social. It has 12 detailed individual indicators, which measure the value of a country's stability and resilience. The environmental value can be partially measured by the Environmental Performance Index (EPI), which includes two factors, environmental health and ecosystem vitality, with 19 objective indicators. $\mathrm{CO}_{2}$ Emission per capita and Ecological Footprint (EFP) are also chosen to measure environmental values and can crosscheck each other. Equality and equity can be partially measured by Income GINI (GIN), Wealth GINI (GIW) and the Gender Gap Index (GGI), which could be found in the World Economic Forum's Inclusive Development Report and the Global Gender Gap Report. In addition, some single indicators, such as the Passport Index (PAI) from Henley \& Partners (H\&P), the Open Defecation Index (ODI) and the Mortality Rate of Traffic Accidents (MRT) from the World Bank are also included. They can be cross compared against each other and measure some values such as international travel convenience (PAI), elegance (ODI), security on the road (MRT) to some extent.

As an important public value, happiness can be measured by the Happiness Index (HAP), the Happy Planet Index (HPI), and the Subjective Well-Being (SWB). These three indicators are linked but with some differences. The HAP is a measurement of subjective well-being compiled by the Earth Institute of Columbia University and the Sustainable Development Solutions Network of the U.N. The SWB is compiled by the Gallup World Poll. It is reasonable to estimate that the HAP and SWB will positively correlate to each other. However, the HPI is calculated by the New Economic Foundation according to the equation (Jeffrey et al., 2016): 


$$
\mathrm{HPI} \approx \frac{(\text { Life Expectancy } \times \text { Subjective Well-Being }) \times \text { Inequality of Outcome }}{\text { Ecological Footprint }}
$$

It does not incorporate economic factors directly but combines life expectancy, SWB (from Gallup), inequality and ecology. Thus, it yields a much different result of country ranking. In 2016, it ranked Costa Rica, Mexico, and Columbia no. 1, 2 and 3 among 140 countries, and Norway 12th, India 50th, China 72nd, the U.S. 108th, and Russia 116th. It suggests that the way choosing and weighting different values will greatly influence the evaluation and perception of good countries.

\subsection{Methods}

Three methods are implemented to explore the sophisticated interrelationships among plural public values and their indicators. The first one is the correlation analysis. Although correlation does not always ensure causation, the theory of data mining suggests that the correlation can indicate and imply the causation, and represent the similarity of two indicators (variables). ${ }^{5}$ The strong and constant correlations among indicators indicate that there must be some common causes and implicit relationships among them (Calude \& Longo, 2016; Cowls \& Schroeder, 2015). The causation can be explored and discovered with a more detailed qualitative analysis.

The second methodology is the principal component analysis (PCA). As we have 30 indicators, the traditional correlation analysis can only depict the relationship between two or several indicators. The PCA can draw the principal components of the 30 indicators, exhibit the sophisticated relationships of these indicators in the multiple dimensions space, and find out which public values play the fundamental roles among their plural counterparts.

The third methodology is the cluster analysis, which is also a new and important data technique based upon correlation analysis and PCA. According to the 30 indicators, countries can be clustered into several groups with similar features and performances. Different from the traditional one-dimensional ranking, the cluster analysis is multiple dimensional, and any country in some specific clusters can identify their development neighbors and clarify their development achievements and insufficiencies. All the correlation analysis, PCA, and the Cluster Analysis are implemented using R packages (ggplot2, factoextra, and factoMineR).

\section{Correlation Analysis}

The relationship among these 30 indicators can be discovered by correlation analysis. These indicators are measuring the performance of different aspects of human society, definitely influencing each other. Their interrelationships can be verified by their strong or medium correlations, as Fig. 1 shows. As the correlations are cross-section data around

\footnotetext{
${ }^{5}$ If two indicators, such as $\mathrm{x}$ and $\mathrm{y}$, have correlation as 1 , such as GDPR and GNIR in this article, it means that they have same information. If the correlation is $\mathrm{r}$, say, 50\%, it means that the two indicators are $50 \%$ similar. The quantitative correlation can indicate the possible causation, while the qualitative analysis can clarify the causation, such as the typical case of beer and diapers. Beer is not the cause of diapers, and vice versa, but they have the common sources.
} 


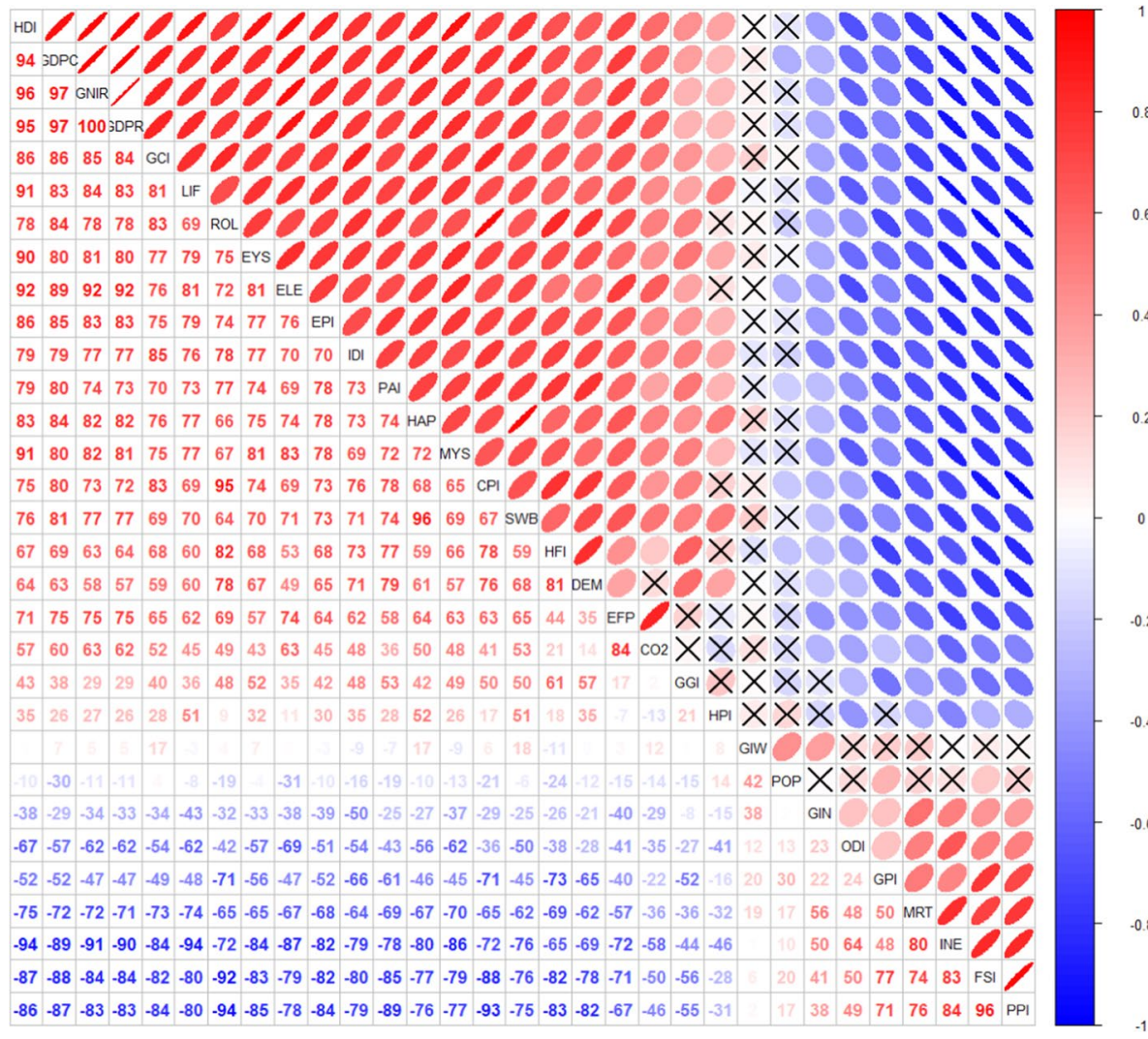

Fig. 1 Correlations of Public Value Indicators. Notes: the full data can be found in Supplementary Material. The correlations unable to pass the significance test (0.05) are marked as X. Because of the unit and scale of these indicators are different, they are all standardized by z-score, and the data of GDPC, GDPR, GNIR, and ELE are also standardized by logarithm

2017-2018, Fig. 2A and B give the time series of GDPC and HDI, demonstrating human society's progress in these two indicators since 1990.

\subsection{Economic Indicators}

The GDPC, GDPR, and GNIR have the strongest correlation coefficients as 0.97, 0.97, and 0.99, respectively. ${ }^{6}$ As Fig. $2 \mathrm{C}$ shows, the GDPR and GNIR can be basically regarded as the same due to their R equaling 0.99. These three indicators can crosscheck each other and guarantee the reliability of the data of the GDP per capita. ${ }^{7}$ In addition, they are supported by the ELE, with R as 0.89 . We can reasonably assume that a rich country measured by GDPC will consume more electricity and possess superior infrastructure.

\footnotetext{
6 If not specified, the correlation coefficient in the article is Pearson correlation coefficient.

7 Because the GDPC, GDPR and GNIR are very similar, we use GDPC to represent them if not identifying.
} 

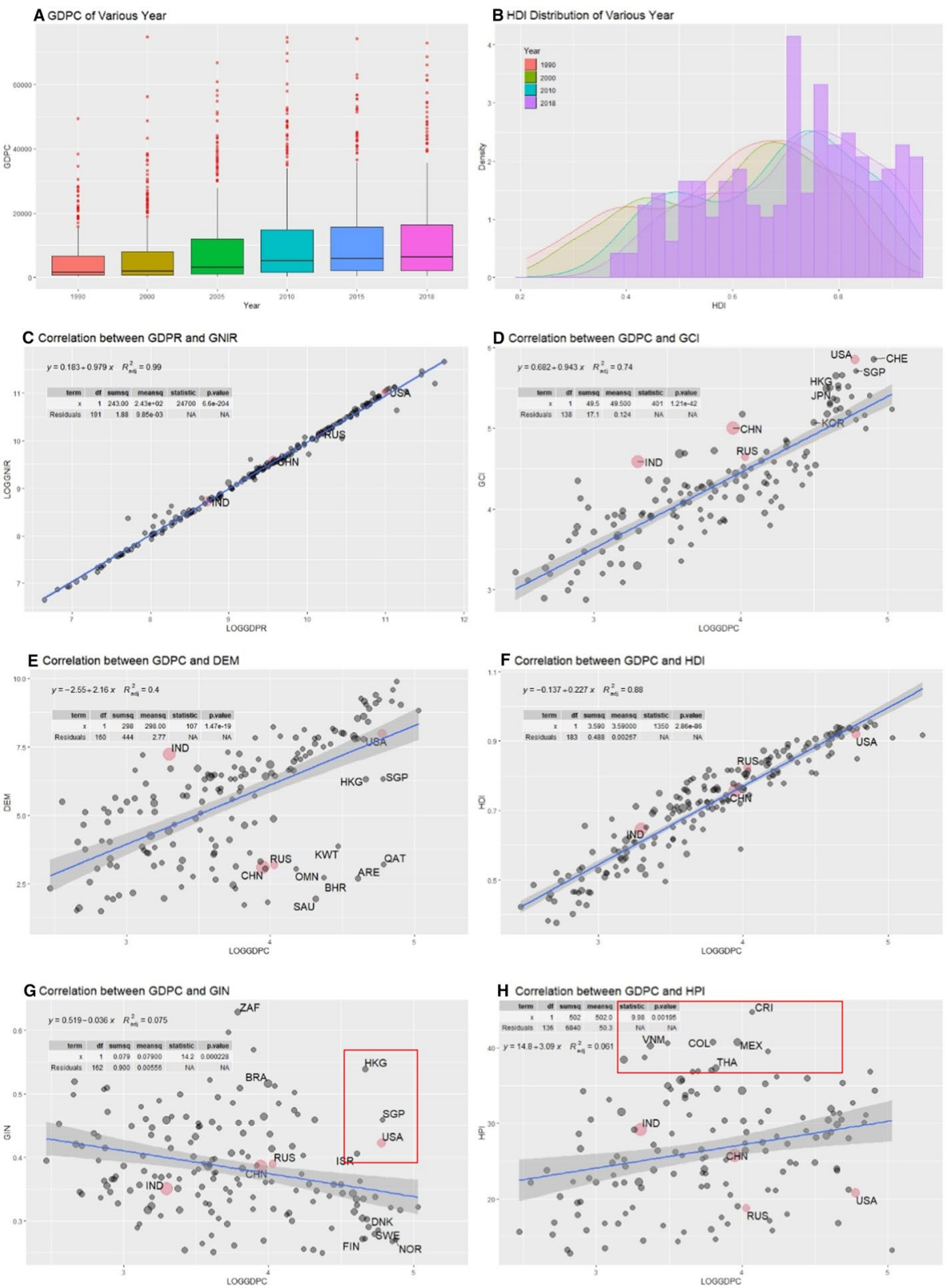

Fig. 2 Correlation among Indicators. Although the R varying, they all pass the t-test and the tendencies are clear

The GDPC can enhance the Global Competitiveness Index (GCI), with correlation coefficient as 0.86 . This correlation indicates that a rich country is generally a competitive country. As Fig. 2D shows, Switzerland (CHE), the USA and Singapore (SGP) are the top three countries on GCI, while China (CHN) and India (IND) also perform well in terms of 
the relationship between GCI and GDPC. These data and rank can verify the superpower of the USA on prosperity and competitiveness, and the potentials of China and India. In contrast, Russia's GDPC $(\$ 10,720)$ is better than India $(\$ 1,981)$ and China $(\$ 8,879)$, while its competitiveness (rank 38) is similar to India (rank 40) and poorer than China (rank 27).

\subsection{Political Indicators}

As indicators of political value, the CPI, DEM, HFI, ROL, GPI and PPI correlate with the GDPC strongly by $0.80,0.63,0.69,0.84,-0.52,-0.87$. Statistically, these strong correlations between economic and political indicators can verify that economic and political values can mutually enhance each other. The explanation is that people will pursue political values such as transparency, democracy, freedom, the rule of law, and peace in the context of sufficient economic growth. Governments ought to satisfy people's demands for these values; otherwise, potential risks and crises may emerge.

The DEM and GPI are not as strongly correlated to GDPC as other indicators $(0.63$ and -0.52 , respectively). The reasons can be clarified by a detailed analysis. As Fig. 2E indicates, six gulf countries, United Arab Emirates (ARE), Qatar (QAT), Kuwait (KWT), Bahrain (BHR), Oman (OMN), and Saudi Arabia (SAU), have high GDPC but low DEM for their different political systems. If these countries are excluded, the correlation of the remaining countries will increase from 0.63 to 0.73 . Particularly, most rich economies with their GDPC above \$31,622 (LOGGDPC > 4.5) have highest democracy, while Hong Kong (HKG) and Singapore (SGP) are the only two outliers.

The GPI, defined as "the absence of violence or the fear of violence", correlates with the GDPC by $-0.52,{ }^{8}$ passing the t-test with the significance of 0.01 . Although not strong, it still supports that a richer country tends to be more peaceful. Additionally, the PPI, defined as "the attitudes, institutions and structures that create and sustain peaceful societies", correlates with the GDPC by -0.87 , strongly supporting that economic values and positive peace can mutually enhance each other.

Meanwhile, the political value indicators strongly correlate with each other. The correlations among CPI, DEM, HFI, ROL, GPI, and PPI range from - 0.65 (DEM and GPI) to 0.95 (CPI and ROL). These strong correlations indicate that transparency, democracy, freedom, the rule of law, and peace mutually support and enhance each other. Thus, it can reasonably claim that a more transparent country statistically tends to be more democratic, free, orderly, and peaceful.

As the correlation can only discover the general tendency, the outliers should be studied as well. The U.S. relatively poor performance on political values measured by the CPI (8.9\%), DEM (12.6\%), HFI (10.7\%), ROL (16.8\%), GPI (70\%), PPI (11.7\%) are not matchable to its excellent performance on economic values measured by the GDPC $(6.3 \%)$ and GCI $(1.4 \%) .{ }^{10}$ These data demonstrate that the U.S. does not perform well on political value among wealthiest countries. As a piece of evidence, the Economist Intelligence

\footnotetext{
8 The GPI and PPI are negative indicators, the higher, the less peace. Iceland ranked no. 1 on GPI by 1.111 , and Syria ranked last by 3.814. So, its correlations with GDPC is negative.

9 Global Peace Index 2020: Measuring Peace in a Complex World, June 2020. https://www.visionofhumanity.org/wp-content/uploads/2020/10/GPI_2020_web.pdf, p.54.

10 The percentage rank is the rank dividing the total number of countries in the ranking. The US ranks 16 on CPI, with 180 countries in the rank. So, the percentage rank $8.9 \%$ means that the US is top $8.9 \%$ on CPI. These percentage ranks are analyzed in supplementary material.
} 
Unit (EIU, 2016, p. 4) noted that "a trust deficit causes the USA to become a "flawed democracy",".

China performed poorly on political indicators, particularly the DEM (83.2\%) and HFI $(81.1 \%)$. These performances can be explained as its slow democratization and liberalization with its fast economic growth (Chen, 2002; Yue, 2008). However, China's development paradigm is debatable and controversial, as its politicians and some scholars do not believe that Western-style democracy is suitable for populous China. China's political system has the feature of meritocracy, alongside its authoritarianism or autocracy (Bell, 2015; Coicaud, 2017; Hankins, 2017). These arguments raise the issue of whether the indicators such as DEM and HFI can precisely measure true democracy and freedom. It is interesting to observe whether Chinese meritocracy can compete against liberal democracy in creating public values in the long run.

In contrast, India performed much better on DEM (25.1\%) and HFI (64.2\%) than China (83.2\% and $81.1 \%$ ), but its relatively good performances on democracy and freedom have not guaranteed its economic and social values, such as the HDI (India 68.3\% vs. China 45.5\%), HAP (79.9\% vs. 56.3\%), and EPI (98.3\% vs. 66.7\%). As Fig. 2E shows, although nearly all developed countries are democratic, developing countries are much more varying on democracy. The cases of China and India reflect the complex priorities of economic and political values, and indicate that democracy alone cannot guarantee economic growth and social development.

Russia has the similar public value performance as China on GDPC (Russia \$10,720 vs. China $\$ 8879$ ), DEM (80.4\% vs. $82.7 \%$ ), HFI (79.2\% vs. $81.8 \%$ ), ROL (78.8\% vs. $66.4 \%$ ). However, one prominent difference between Russia and China is that the annual growth rate of GDPC from 2005 to 2015 of China is $16.5 \%$, while Russia is 5.7\%. This indicates that Russia has a much better economic basis but slower economic growth during the last several years. Whether and how to improve the political values is a great challenge for China and Russia.

\subsection{Social Indicators}

Social values are more diverse than economic and political ones. Most social values can be enhanced by economic and political values because when people become richer, they tend to pursue better education, health, environment, and equity. The correlation analyses basically support this expectation. The correlation coefficients of the GDPC and GCI to the HDI are 0.94 and 0.86 , as Fig. $2 \mathrm{~F}$ shows. These correlations verify that the rich and competitive countries are generally those with high human development level measured by the HDI. The GDPC and the GCI also have strong correlations with the Inclusive Development Index (IDI) at 0.79 and 0.85 respectively. These correlations imply that the GDP per capita is the foundation of the HDI and IDI.

Economic equity, as a part of equity and justice, can be measured by income Gini coefficient (GIN) and wealth Gini coefficient (GIW). The correlation coefficient between the GDPC and GIN is -0.29 , weak but passing the t-test. It can be explained by the Fig. $2 \mathrm{G}$. Those relatively poorer countries with GDPC below \$31,622 (LOGGDPC < 4.5) are much more varying in GIN than rich countries. Specifically, nearly all rich countries can keep their GIN below 0.35 , particularly the Nordic countries, with the exceptions such as the USA (0.42), Israel (ISR, 0.41), Singapore (SGP, 0.46) and Hong Kong SAR (HKG, 0.54). African countries such as South Africa (ZAF, 0.63) and South American countries such as Brazil (0.52) maintain a very high GIN. China's economic inequality has been serious 
around 2010 with the GIN mounting to 0.44 , but gradually declined to 0.38 with the effective policy of poverty reduction and social justice enhancement (Wu \& Ramesh, 2014). Although the correlation between GDPC and GIN is weak, it still can verify that richer countries tend to be more equal.

Gender equality is another facet of equity and can be partially measured by Gender Gap Index (GGI). It has a positive but not very strong correlation with GDPC at 0.38 , passing the t-test. Similar as GIN, poor countries with a GDPC below $\$ 20,000$ have much more varying GGI than rich countries. Among the rich countries, the USA performs rather poorly on GGI (percentage rank 34.0\%), while Russia (49.3\%), China (69.4\%) and India (73.6\%) perform not well but do not deviate much from their relatively poor economies. A surprising finding is that poor countries such as Rwanda (RWA, 2.8\%), Nicaragua (NIC, $4.2 \%$ ), and Namibia (NAM, 9.2\%) have excellent GGI performances. Their performances can demonstrate that poor countries can also obtain some public values, such as gender equality.

Subjective happiness, measured by the Happiness Index (HAP) and Subjective Wellbeing (SWB), are strongly correlated with GDPC by 0.84 and 0.81 . These two indicators can support and crosscheck each other, and verify that the economic value is the dominant factor of subjective happiness. People in richer countries statistically tend to be happier than people in poorer countries. However, the Happy Planet Index (HPI) tells another story. The correlations between HPI and GDPC is 0.262 , passing the $t$ test. The basic reason is that the happiness measured by HPI is much different from that of HAP and SWB. The HPI encompasses life expectancy, inequality, and ecological footprint, more comprehensive than the HAP and SWB. Consequently, as Fig. 2H shows, most Latin-American countries such as Costa Rica (rank 1), Mexico (rank 2), Columbia (rank 3), and some Asian countries such as Vietnam (rank 5) and Thailand (rank 9) perform rather well. In contrast, India (rank 50), China (rank 72), the U.S. (rank 108) and Russia (rank 116) perform poorly. As rich countries tend to consume more ecological footprints, their performance on the HPI are low relative to the GDPC. This is demonstrated by the following rankings: Norway (rank 12), Switzerland (rank 24), and Denmark (rank 32). This finding corroborates that the value standard will greatly alter the perception and evaluation of country performance.

Environmental values can be partially measured by the ecological footprint (EFP), Carbon Emissions per capita (CO2) and Environmental Performance Index (EPI). The correlation between these indicators and GDPC are $0.75,0.60$ and 0.85 , respectively. It can reasonably be explained that the modern economy is achieved at the cost of ecology. The richer country will generally consume more EFP and CO2. As outliers, Norway, Switzerland, and Ireland perform rather well on the EFP and CO2, while the U.S. is the poorest on these indicators among rich countries, better than only Luxembourg, Qatar, and Australia. Comparatively, Russia, China and India are neither excellent nor extravagant on the EFP and $\mathrm{CO} 2$ relative to their economies. Comparably, the EPI has a strong positive correlation with GDPC at 0.85 . This indicates that richer countries statistically tend to enjoy a better environment measured by EPI. Once again, the U.S. is the poorest among rich countries, better than only Qatar, while Russia, China and India are not excellent but not deviate much from their relatively poor economies.

Finally, the correlation coefficients between GDPC and Passport Index (PAI), Open Defecation Index (ODI), Mortality Rate of Traffic Accidents (MRT), life expectancy (LIF), and Inclusive Development Index (IDI) are 0.80, - 0.57, - 0.72, 0.83, 0.79, quite strong. These results verify that richer countries tend to enjoy more convenience of international travel, elegance, road safety, life expectancy, and inclusive development. Interestingly, India ranked 180 among 198 countries on open defecation index (ODI), verifying that 
hygiene has been a serious problem in India. China's ODI ranked no. 97. The governments of India and China may compete on creating the public value of clean toilets, sanitation, and good hygiene habits of their citizens, as hygiene and health are also important public values.

\section{Principal Component Analysis (PCA)}

The correlation analysis can only discover the relationship between two indicators. The PCA can further explore the complex relationships among the 30 indicators and their public values, and draw the main information of the indicators (Saukani \& Ismail, 2019).

The Kaiser-Meyer-Olkin (KMO) can test the adequacy and significance ( $p$ value) of data of the 30 indicators. It shows that the adequacy is 0.91 , and the p.value is 0.000 . This verifies that the 30 indicators can be analyzed by the PCA. As Fig. 3 shows, the first principal component (Dim. 1) can explain 65.8\% variance of the 30 indicators, while the top four can explain $83.6 \%$. Because of the strong and moderate correlations among these indicators, most indicators are closely surrounding Dim. 1, from SWB to CO2 (positive correlation), and from MRT to PPI (negative correlation), with the only exception as HPI, GIN, and GIW, which have weak correlations with the Dim. 1. Because all the indicators are scaled, their angles reflect their correlations. Actually, the 30 indicators are forming a 30-dimension space, and the short ones, say, GIW and GIN, means their variances are mainly projected in other dimensions and planes. The $65.8 \%$ variance of the 30 indicators are converged to Dim. 1, which can be named as economic dimension, meaning that the economic value dominates the $65.8 \%$ information of these 30 indicators. The HPI basically forms the Dim. 2, perpendicular to Dim. 1, and represents $6.6 \%$ information of these 30 indicators. It can be named as the ecological happiness dimension. Similarly, the Dim. 3 is mainly from the GIW, and representing $6.2 \%$ of the information. It can be named as the wealth equity dimension. The Dim. 4 is mainly from ODI and representing $5.0 \%$ of the information, and can be named as elegance dimension. The remaining $16.37 \%$ of the information in other 26 dimensions can be reduced. This analysis verifies that economic value is the most important principal component of the 30 indicators, and that ecological happiness as a social value is the second most important. Other values are not trivial, but most of their information can be integrated into economic values.

Countries can be scored according to these 4 principal components. As these 4 principal components are orthogonal, they do not have the multicollinearity problem and can be summarized according to their scores on the four independent subjects. ${ }^{11}$ The detailed scores and calculation can be found in Supplementary Material, and the final score and rank of the 61 countries is listed in "Appendix".

In contrast to the rankings by single indicators such as the GDPC or HDI, the ranking in "Appendix" incorporates all the public values measured by the 30 indicators, and so it is more comprehensive. The basic ranking does not change considerably, because the economic value still dominates all the values and the 30 indicators. The Nordic countries, such as Norway, Denmark, and Sweden, are still at the top, and some African countries such as Cameroon, Nigeria, and Senegal are at the bottom. However, there are still some interesting findings. The USA slipped sharply from no. 2 in GDPC and no. 11 in HDI to no. 37 in this

${ }^{11}$ This scoring of countries is something like students taking some examination with several subjects. 
Fig. 3 PCA of 30 indicators
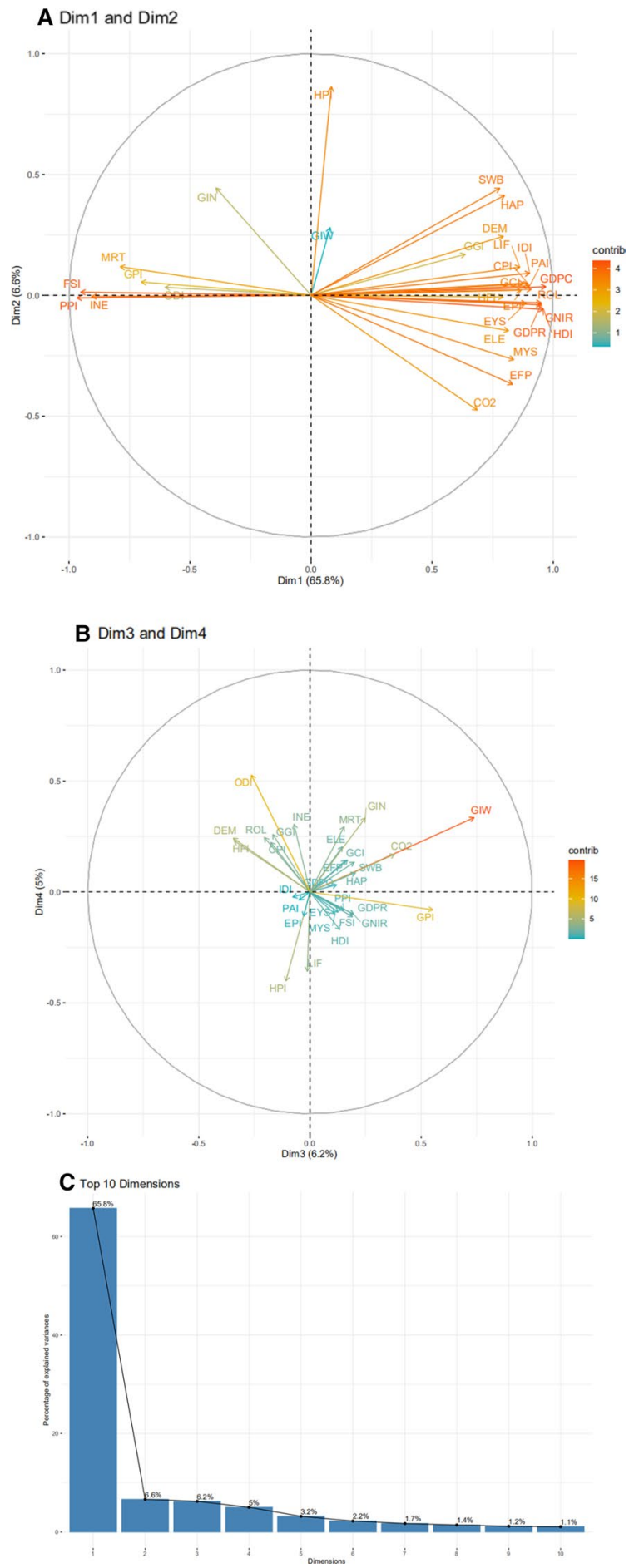
new ranking. Russia has also dropped greatly, from no. 29 on GDPC and no. 25 on HDI to no. 54. China has also gone from no. 34 in GDPC and no. 43 in HDI to no. 47. India, with its relatively low ranking on GDPC and HDI at both no. 53, drops to no. 58. These ranking changes indicate that the USA, Russia, and China are experiencing unbalanced development measured by the 30 indicators. In contrast, some countries, such as Costa Rica (from no. 22 and 27 to 11), Colombia (from no. 38 and 40 to 32), Kyrgyz (from no. 59 and 51 to 40), Bangladesh (from no. 55 and 54 to 43), exhibit prominent improvements in this new ranking system. These countries are not so rich with regard to GDPC, but they enjoy balanced development and some specific benefits such as happiness and equity.

\section{Cluster Analysis}

Similar to the PCA, the cluster analysis can further complement and be compared against the PCA (D'Urso, 2020; Everitt, 2011). By defining the distance as the differences of countries on indicators such as GDPC, population, geography, and culture, ${ }^{12}$ some countries can be regarded as more similar than others and can be clustered together. For example, developed and developing countries, populous and sparsely populated countries, African and European countries, may be clustered together. But these classifications are single-dimensional. The cluster analysis can aggregate the distance of multiple dimensions and classify the cases by their distances. It includes the hierarchical cluster, in which the number of clusters is automatically generated by the data and algorithm, and K-means clustering, in which the number of clusters should be set in advance. We use both of them to crosscheck and observe which countries are more similar by the 30 public value indicators and the corresponding public values. The clustering of countries can help governments position themselves, find their development neighbors and identify development gaps.

As Fig. 4A. shows, these 61 countries can be clustered into two basic groups according to the hierarchical cluster, with 34 in Group 1 and 27 in Group 2, basically consistent to the ranking in the "Appendix". These two groups can be further clustered into six smaller subgroups with closer similarity. The traditional developed countries have more similarities and are automatically clustered by algorithm, enjoying the highest economic value in dimension 1 in Fig. 4B, although they still have some differences. For example, the Nordic countries and Western European countries are more closely grouped, while Canada (CAN), Australia (AUS), Belgium (BEL) and the USA are closer. Interestingly, in K-Means clustering, Japan (JPN) and South Korea (KOR) are clustered together, not with Western countries, but with some east and central European countries such as Czech (CZE), Slovenia (SVN), Poland (POL), Spain (ESP), and Portugal (PRT). This grouping is reasonable and understandable because, as Fig. 4B shows, their subgroups perform worse on the economic value dimension.

In the Fig. 4B K-Means Cluster, Latin American countries such as Costa Rica (CRI), Brazil (BRA), Panama (PAN), Columbia (COL), Mexico (MEX), are closer and grouped in the same cluster, enjoying the highest ecological happiness on dimension 2. Uruguay (URY) and Chile are close but clustered in another group because they have better

\footnotetext{
12 For example, the GDPC of the US, the UK, and China are $\$ 59,957, \$ 40,361, \$ 8879$ in 2017 , so the distance of the US and the UK is shorter, and more similar, than that of the US and China. In the same way, if we can measure the culture by some indicators, we can claim that the US and the UK are more similar than the US and China.
} 


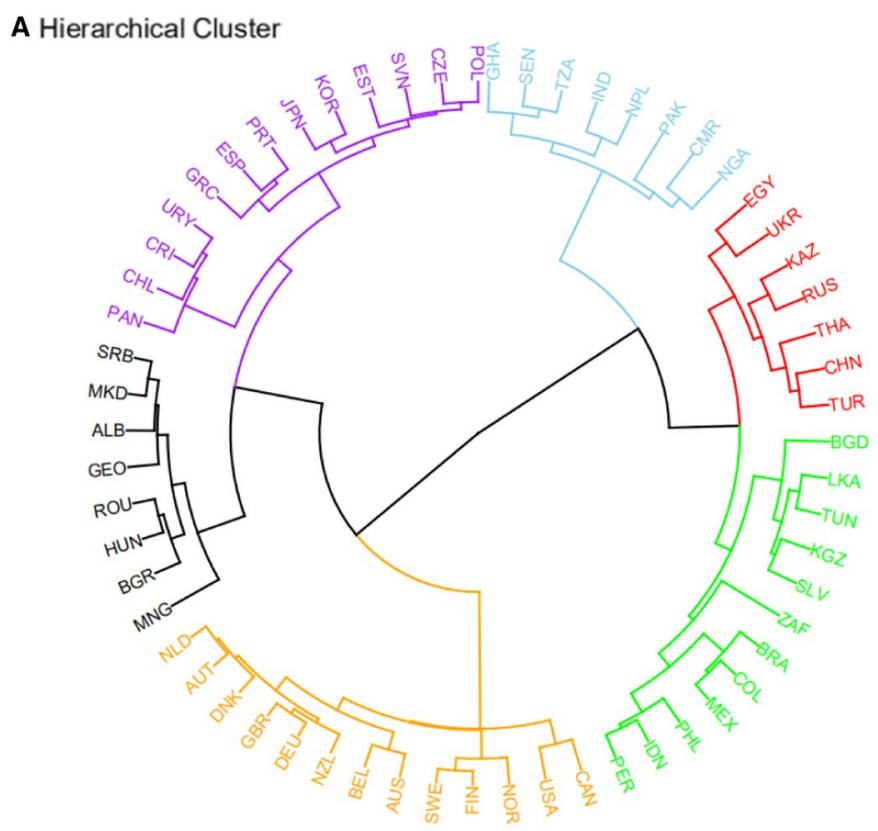

B K-Means Cluster by Six Group

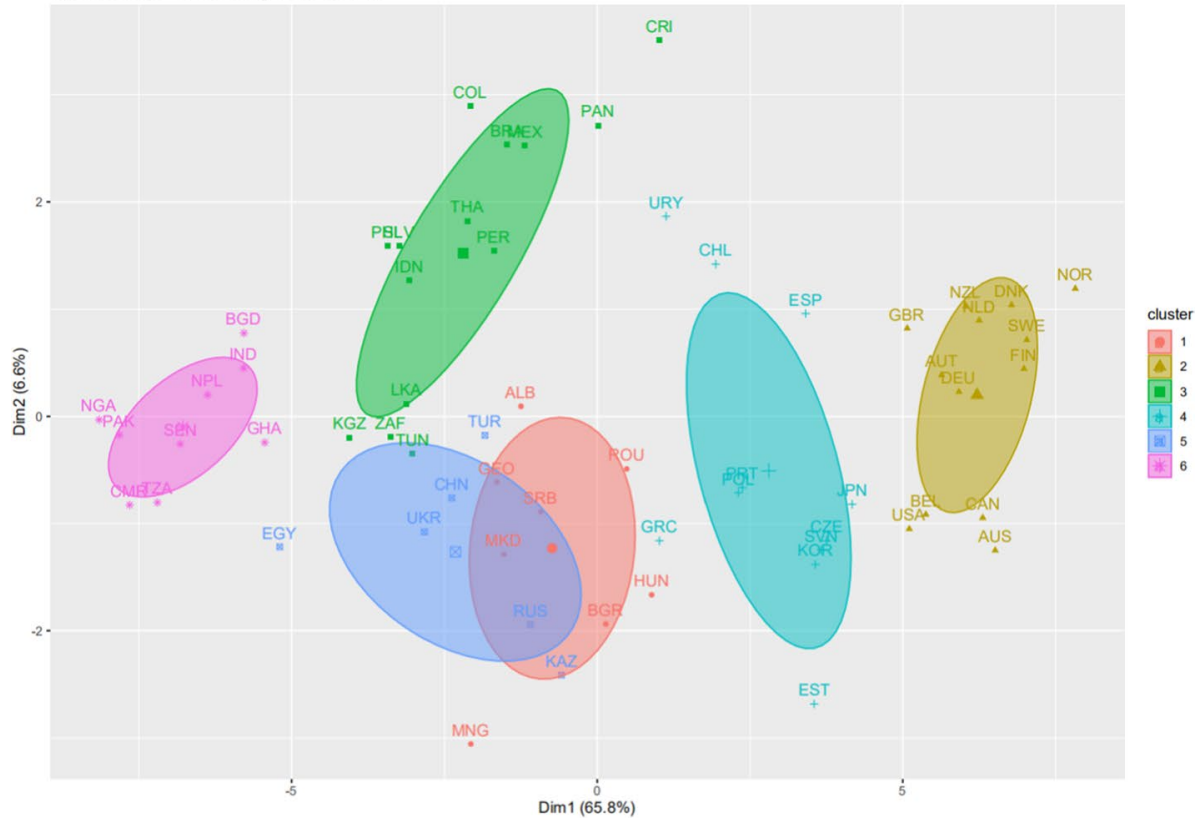

Fig. 4 Hierarchical cluster and K-means cluster

economies. Most African countries, such as Cameroon (CMR), Nigeria (NGA), Senegal (SEN), Tanzania (TZA), and some poorest South Asian countries such as India (IND), Bangladesh (BGD), Nepal (NPL), and Pakistan (PAK) are clustered together. This 
subgroup has the poorest economic levels and moderate ecological happiness, as shown in Fig. 4B. Russia (RUS), China (CHN), Turkey (TUR), Kazakhstan (KAZ), Ukraine (UKR), and Egypt (EGY) are grouped together because they have moderate economic levels but the poorest ecological happiness. Every country can find its development positions and neighbors in these cluster maps. It is noticeable that geography greatly impacts the cluster of countries, although some exceptions remain. This can be explained by the tendency of neighboring countries to learn from and impact each other. Although these cluster maps are not strict and precise, they can help in recognizing which are a country's development neighbors and where one's advantages and disadvantages lie.

\section{Conclusion}

Human society has created huge amounts of material wealth and made great progress in science and technology, but has not achieved similar advancement in happiness, equity, peace and environmental sustainability. This deficiency can be explained and remedied by the public value theory. Social development stems from public values, and all the social spheres need to improve orderly and synchronously. Politicians and governments should arrange priorities according to complex and plural public values; otherwise, development failures and social crises are inevitable.

Existing economic, political, and social indicators have explicit or implicit public value foundations and can measure the performance of countries and governments according to various value dimensions. We collected 30 development indicators and found that most of these indicators have strong or moderate correlations. Through PCA, we further discovered that economic value could explain $65.8 \%$ of the information in these 30 indicators. This means that economic value is the basis of these indicators and their related public values. Although other public values such as equity and environmental protection are important (Wang \& Christensen, 2017), they are still correlated with and based upon economic values. We also explored the public value combinations by cluster analysis and classified 61 countries into several typical groups. This cluster can position countries and identify their similarities and differences, and help them cognize their development neighbors and clarify their advantages and disadvantages.

Competition among countries can be viewed as the competition of their capability to create public values. If one country is viewed as better than another, it means that its government has created better public values in some aspects. Every country has its advantages and disadvantages. Some major countries, such as the U.S., China, Russia, and India, have their merits in some specific public values but are also insufficient in other specific public values. Thus, they are experiencing unbalanced developments. Some countries, such as Costa Rica, also have distinguished public values such as ecological happiness and gender equality. The public value theory can help politicians and governments identify their specific achievements and problems, and then find some solutions and establish policies. Creating and balancing various values is one of their most crucial challenges. ${ }^{13}$

The ultimate goal of social development can be understood as making the world better by creating public values. Further studies may include more accurate measurements

\footnotetext{
13 In a recent article (Wu \& Chou, 2021), even in a homogeneous Asian context such as Hong Kong where the vast majority of the population is Chinese, the government also needs to balance various values carefully.
} 
of public values, and the public value evaluation of specific public policies and human behaviors. Beside clarifying what public value is and how to measure it, the creation and deliberation of public values have presented greater challenges for not only politicians but also businessmen, social activists, and individuals. If humankind can collaborate, deliberate, introspect, and learn from each other, we can create public values and improve the quality of our countries and the world.

\section{Appendix: Country Scores and Ranks}

\begin{tabular}{|c|c|c|c|c|c|c|}
\hline Country Name & Country Code & Score & Rank & $\begin{array}{l}\text { Rank Differ- } \\
\text { ence from } \\
\text { GDPC }\end{array}$ & $\begin{array}{l}\text { Rank Differ- } \\
\text { ence from } \\
\text { HDI }\end{array}$ & GDP Rank HDI Rank \\
\hline
\end{tabular}

\begin{tabular}{|c|c|c|c|c|c|c|c|}
\hline Norway & NOR & 8.15 & 1 & 0 & 0 & 1 & 1 \\
\hline Denmark & DNK & 7.82 & 2 & 1 & 4 & 3 & 6 \\
\hline Netherlands & NLD & 7.51 & 3 & 3 & 2 & 6 & 5 \\
\hline New Zealand & NZL & 7.00 & 4 & 8 & 5 & 12 & 9 \\
\hline Sweden & SWE & 6.99 & 5 & 0 & -1 & 5 & 4 \\
\hline Finland & FIN & 6.74 & 6 & 2 & 1 & 8 & 7 \\
\hline $\begin{array}{l}\text { United King- } \\
\text { dom }\end{array}$ & GBR & 6.28 & 7 & 6 & 3 & 13 & 10 \\
\hline Spain & ESP & 6.26 & 8 & 8 & 9 & 16 & 17 \\
\hline Austria & AUT & 5.98 & 9 & -2 & 5 & 7 & 14 \\
\hline Germany & DEU & 5.81 & 10 & 0 & -8 & 10 & 2 \\
\hline Costa Rica & CRI & 5.41 & 11 & 16 & 22 & 27 & 33 \\
\hline Belgium & BEL & 5.00 & 12 & -1 & 0 & 11 & 12 \\
\hline Slovenia & SVN & 4.80 & 13 & 4 & 3 & 17 & 16 \\
\hline Japan & JPN & 4.74 & 14 & 0 & -1 & 14 & 13 \\
\hline Uruguay & URY & 4.60 & 15 & 7 & 14 & 22 & 29 \\
\hline Australia & AUS & 4.29 & 16 & -12 & -13 & 4 & 3 \\
\hline Czech Republic & CZE & 3.85 & 17 & 3 & 1 & 20 & 18 \\
\hline Canada & CAN & 3.25 & 18 & -9 & -10 & 9 & 8 \\
\hline Portugal & PRT & 3.14 & 19 & -1 & 3 & 18 & 22 \\
\hline Albania & ALB & 3.07 & 20 & 22 & 14 & 42 & 34 \\
\hline Hungary & HUN & 2.87 & 21 & 4 & 3 & 25 & 24 \\
\hline Chile & CHL & 2.62 & 22 & 2 & 1 & 24 & 23 \\
\hline Panama & PAN & 2.42 & 23 & 0 & 9 & 23 & 32 \\
\hline Poland & POL & 2.19 & 24 & 2 & -3 & 26 & 21 \\
\hline Romania & ROU & 2.08 & 25 & 3 & 3 & 28 & 28 \\
\hline Korea, Rep & KOR & 1.48 & 26 & -11 & -11 & 15 & 15 \\
\hline Estonia & EST & 1.10 & 27 & -8 & -8 & 19 & 19 \\
\hline Greece & GRC & 0.85 & 28 & -7 & -8 & 21 & 20 \\
\hline Mexico & MEX & 0.75 & 29 & 3 & 8 & 32 & 37 \\
\hline Serbia & SRB & 0.17 & 30 & 9 & 1 & 39 & 31 \\
\hline Bulgaria & BGR & 0.05 & 31 & 4 & -4 & 35 & 27 \\
\hline Colombia & $\mathrm{COL}$ & 0.01 & 32 & 6 & 8 & 38 & 40 \\
\hline
\end{tabular}




\begin{tabular}{|c|c|c|c|c|c|c|c|}
\hline Country Name & Country Code & Score & Rank & $\begin{array}{l}\text { Rank Differ- } \\
\text { ence from } \\
\text { GDPC }\end{array}$ & $\begin{array}{l}\text { Rank Differ- } \\
\text { ence from } \\
\text { HDI }\end{array}$ & GDP Rank & HDI Rank \\
\hline Peru & PER & -0.07 & 33 & 3 & 9 & 36 & 42 \\
\hline El Salvador & SLV & -0.68 & 34 & 11 & 18 & 45 & 52 \\
\hline Brazil & BRA & -0.73 & 35 & -4 & 4 & 31 & 39 \\
\hline N. Macedonia & MKD & -0.84 & 36 & 5 & 5 & 41 & 41 \\
\hline United States & USA & -0.84 & 37 & -35 & -26 & 2 & 11 \\
\hline Georgia & GEO & -0.85 & 38 & 5 & -3 & 43 & 35 \\
\hline Sri Lanka & LKA & -0.94 & 39 & 5 & -3 & 44 & 36 \\
\hline $\begin{array}{l}\text { Kyrgyz Repub- } \\
\text { lic }\end{array}$ & KGZ & -2.08 & 40 & 19 & 11 & 59 & 51 \\
\hline Thailand & THA & -2.08 & 41 & -4 & -3 & 37 & 38 \\
\hline Indonesia & IDN & -2.11 & 42 & 4 & 6 & 46 & 48 \\
\hline Bangladesh & BGD & -2.14 & 43 & 12 & 11 & 55 & 54 \\
\hline Tunisia & TUN & -2.40 & 44 & 4 & 1 & 48 & 45 \\
\hline Philippines & PHL & -2.58 & 45 & 4 & 2 & 49 & 47 \\
\hline Turkey & TUR & -3.31 & 46 & -16 & -16 & 30 & 30 \\
\hline China & $\mathrm{CHN}$ & -4.73 & 47 & -13 & -4 & 34 & 43 \\
\hline Ukraine & UKR & -4.97 & 48 & 2 & -4 & 50 & 44 \\
\hline Nepal & NPL & -5.24 & 49 & 12 & 7 & 61 & 56 \\
\hline Mongolia & MNG & -5.53 & 50 & -3 & -4 & 47 & 46 \\
\hline Kazakhstan & KAZ & -6.26 & 51 & -18 & -25 & 33 & 26 \\
\hline Ghana & GHA & -6.55 & 52 & 0 & 3 & 52 & 55 \\
\hline Pakistan & PAK & -6.67 & 53 & 3 & 5 & 56 & 58 \\
\hline Russian & RUS & -6.88 & 54 & -25 & -29 & 29 & 25 \\
\hline Egypt & EGY & -7.03 & 55 & -4 & -5 & 51 & 50 \\
\hline Tanzania & TZA & -7.04 & 56 & 4 & 4 & 60 & 60 \\
\hline Senegal & SEN & -7.24 & 57 & 1 & 4 & 58 & 61 \\
\hline India & IND & -7.34 & 58 & -5 & -5 & 53 & 53 \\
\hline South Africa & ZAF & -8.64 & 59 & -19 & -10 & 40 & 49 \\
\hline Nigeria & NGA & -10.72 & 60 & -6 & -1 & 54 & 59 \\
\hline Cameroon & CMR & -10.83 & 61 & -4 & -4 & 57 & 57 \\
\hline
\end{tabular}

Sixty-one countries are included in the ranking. The GDPPC and HDI rankings are those of the 61 included countries

Supplementary Information The online version contains supplementary material available at https://doi. org/10.1007/s11205-021-02805-5.

Acknowledgements This research is funded by the National Natural Science Foundation of China (71673092). Thanks for the blind reviewers' helpful and kindly suggestions, and for the editors' patient proofreading.

\section{Declarations}

Competing interests The authors declare that they have no competing interests. 
Open Access This article is licensed under a Creative Commons Attribution 4.0 International License, which permits use, sharing, adaptation, distribution and reproduction in any medium or format, as long as you give appropriate credit to the original author(s) and the source, provide a link to the Creative Commons licence, and indicate if changes were made. The images or other third party material in this article are included in the article's Creative Commons licence, unless indicated otherwise in a credit line to the material. If material is not included in the article's Creative Commons licence and your intended use is not permitted by statutory regulation or exceeds the permitted use, you will need to obtain permission directly from the copyright holder. To view a copy of this licence, visit http://creativecommons.org/licenses/by/4.0/.

\section{References}

Ackerman, F., \& Heinzerling, L. (2005). Priceless: On knowing the price of everything and the value of nothing. New Press.

Allison, G. (2017). China vs. America. Foreign Affairs, 96(5), 80-89.

Anderson, E. (1993). Value in ethics and economics. Harvard University Press.

Attfield, R. (1998). Existence value and intrinsic value. Ecological Economics, 24(2-3), 163-168.

Beck Jørgensen, T., \& Bozeman, B. (2007). Public values: An inventory. Administration \& Society, 39(3), 354-381.

Bell, D. A. (2015). The China model: Political meritocracy and the limits of democracy. Princeton University Press.

Berg, M., \& Lidskog, R. (2018). Deliberative democracy meets democratised science: A deliberative systems approach to global environmental governance. Environmental Politics, 27(1), 1-20.

Booth, K. I. (2013). Deep ecology, hybrid geographies, and environmental management's relational premise. Environmental Values, 22(4), 523-543.

Borins, S. (1995). The new public management is here to stay. Canadian Public Administration, 81(1), $122-132$.

Bozeman, B., \& Johnson, J. (2015). The political economy of public values: A case for the public sphere and progressive opportunity. American Review of Public Administration, 45(1), 61-85.

Brubaker, R. (2017). Why populism? Theory and Society, 46(5), 357-385.

Bryson, J. M., Crosby, B. C., \& Bloomberg, L. (2014). Public value governance: Moving beyond traditional public administration and the new public management. Public Administration Review, 74(3), 445-456.

Butler, W. F., \& Acott, T. (2007). An inquiry concerning the acceptance of intrinsic value theories of nature. Environmental Values, 16(2), 149-168.

Calude, C. S., \& Longo, G. (2016). The Deluge of spurious correlations in big data. Foundations of Science, $1-18$.

Campbell, N., \& Witcher, M. (2015). Political entrepreneurship: Jefferson, Bayard, and the election of 1800. Journal of Entrepreneurship and Public Policy, 4(3), 298-312.

Chang, R. (1997). Incommensurability, incomparability, and practical reason. Harvard University Press.

Chen, A. (2002). Capitalist development, entrepreneurial class, and democratization in China. Political Science Quarterly, 117(3), 401-422.

Coicaud, J. M. (2017). Debating Daniel A. Bell: On political meritocracy and democracy in China and beyond. Philosophy and Public Issues, 7(1), 15-51.

Cooper, A. F., \& Farooq, A. (2015). The advocacy of democratic governance by India and China: Patterns of consistency/inconsistency between declaratory and operational practices. India Quarterly, 71(3), 221-238.

Cowls, J., \& Schroeder, R. (2015). Causation, correlation, and big data in social science research. Policy and Internet, 7(4), 447-472.

D’Urso, P., De Giovanni, L., Disegna, M., et al. (2020). A tourist segmentation based on motivation, satisfaction and prior knowledge with a socio-economic profiling: A clustering approach with mixed information. Social Indicators Research. https://doi.org/10.1007/s11205-020-02537-y

de Graaf, G., Huberts, L., \& Smulders, R. (2016). Coping with public value conflicts. Administration \& Society, 48(9), 1-27.

Dryzek, J. S., et al. (2019). The crisis of democracy and the science of deliberation. Science, 363(6432), 1144-1146.

Dunleavy, P., \& Hood, C. (1994). From old public administration to new public management. Public Money \& Management, 14(3), 9-16. 
EIU (Economist Intelligence Unit). (2016). Democracy Index 2016: Revenge of the "deplorables". https:// www.eiu.com/public/topical_report.aspx?campaignid=DemocracyIndex 2016 .

Elkington, J. (1999). Cannibals with Forks: The triple bottom line of 21 century business. Capstone.

Everitt, B. S., et al. (2011). Cluster analysis. Wiley.

Faulkner, N., \& Kaufman, S. (2017). Avoiding theoretical stagnation: A systematic review and framework for measuring public value. Australian Journal of Public Administration, 77(1), 69-86.

Fishkin, J. S. (2018). Democracy when the people are thinking: Revitalizing our politics through public deliberation. Oxford University.

Frankena, W. K. (1973). Ethics (second edition). Prentice Hall.

Fukuyama, F. (2014). Political order and political decay: From the industrial revolution to the globalization of democracy. Farrar Straus Giroux.

Goodin, R. E. (2017). The epistemic benefits of deliberative democracy. Policy Sciences, 50(3), 351-366.

Gwartneya, J., \& Lawson, R. (2003). The concept and measurement of economic freedom. European Journal of Political Economy, 19, 405-430.

Hankins, J. (2017). Reforming elites the Confucian way. American Affairs, 1(2), 45-57.

Harris, S. (2010). The moral landscape: How science can determine human value. Free Press.

Hawley, P. (2008). Moral absolutism defended. Journal of Philosophy, 105(5), 273-275.

Hazen, H. (2008). Of outstanding universal value: The challenge of scale in applying the World Heritage Convention at national parks in the U.S. Geoforum, 39(1), 252-264.

Ikenberry, G. J. (2017). The plot against American foreign policy. Foreign Affairs, 96(3), 2-9.

Inglehart, R. F. (2008). Changing values among western publics from 1970 to 2006. West European Politics, 31(1), 130-146.

Jacobs, G., \& Cleveland, H. (1999). Social development theory. International Center for Peace and Development. http://www.icpd.org/development_theory/SocialDevTheory.htm.

Jacques, M. (2012). When China rules the world: The end of the western world and the birth of a new global order. Penguin Group.

Jeffrey, K., Wheatley, H., \& Abdallah, S. (2016). The Happy Planet Index: 2016 A global index of sustainable well-being. New Economics Foundation.

Ketchen, D. J., \& Shook, C. L. (1996). The application of cluster analysis in strategic management research: An analysis and critique. Strategic Management, 17(6), 441-458.

Kissinger, H. (2014). World order. Penguin Group.

Kopnina, H., \& Cherniak, B. (2015). Cultivating a value for non-human interests through the convergence of animal welfare, animal rights, and deep ecology in environmental education. Education Sciences, 5(4), 363-379.

Kosack, S. (2014). The logic of pro-poor policymaking: Political entrepreneurship and mass education. British Journal of Political Science, 44(2), 409-444.

Loubser, R., \& Steenekamp, C. (2017). Democracy, well-being, and happiness: A 10-nation study. Journal of Public Affairs, 17(1-2), e1646.

Manning, N. (2001). The legacy of new public management in developing countries. International Review of Administrative Sciences, 67(2), 297-312.

Marples, D. R. (2004). The collapse of the Soviet Union, 1985-1991. Routledge.

Maslow, A. H. (1943). A theory of human motivation. Psychological Review, 50(4), 370-396.

Moen, O. M. (2016). An argument for intrinsic value monism. Philosophia, 44(4), 1375-1385.

Moore, M. (1995). Creating public value: Strategic management in government. Harvard University Press.

Moore, M. (2014). Public value accounting: Establishing the philosophical basis. Public Administration Review, 74(4), 465-477.

Næss, A. (1973). The shallow and the deep, long-range ecology movement. Inquiry, 16, 95-100.

O’Flynn, J. (2007). From new public management to public value: Paradigmatic change and managerial implications. The Australian Journal of Public Administration, 66(3), 353-366.

Oldenhof, L., Postma, J., \& Putters, K. (2014). On justification work: How compromising enables public managers to deal with conflicting values. Public Administration Review, 74(1), 52-63.

Osborne, D., \& Gaebler, T. (1992). Reinventing government: How the entrepreneurial spirit is transforming the public sector. Penguin Books.

Overeem, P., \& Tholen, B. (2011). After managerialism: Macintyre's lessons for the study of public administration. Administration \& Society, 43(7), 722-748.

Piketty, T. (2017). Capital in the twenty-first century. Harvard University Press.

Popper, K. (1972). Objective knowledge: An evolutionary approach. Clarendon Press.

Rana, K. S. (2017). India and China in Asia. China Report, 53(2), 87-106.

Rojas, L. I. (2015). Culture through the state: Law and policy as a frame to culture. Journal of Social Policy Studies, 13(1), 137-148. 
Rokeach, M. (1973). The nature of human values. The Free Press.

Sagar, R. (2015). Against moral absolutism: Surveillance and disclosure after Snowden. Ethics \& International Affairs, 29(2), 145-159.

Saukani, N., \& Ismail, N. A. (2019). Identifying the components of social capital by categorical principal component analysis (CATPCA). Social Indicators Research, 141, 631-655.

Schaffer, J. (2014). Monism. Stanford Encyclopedia of Philosophy. https://plato.stanford.edu/entries/ monism/.

Scherer, A. G., Rasche, A., \& Palazzo, G. (2016). Managing for political corporate social responsibility: New challenges and directions for PCSR 2.0. Journal of Management Studies, 53(3), 273-298.

Schwab, K. (2012). The global competitiveness report 2011-2012. Geneva: World Economic Forum.

Schwartz, S. H. (1994). Are there universal aspects in the content and structure of values? Journal of Social Issues, 50, 19-45.

Schwartz, S. H., \& Boehnke, K. (2004). Evaluating the structure of human values with confirmatory factor analysis. Journal of Research in Personality, 38, 230-255.

Shambaugh, D. (2016). Contemplating China's future. Washington Quarterly, 39(3), 121-130.

Sheehy, B. (2015). Defining CSR: Problems and solutions. Journal of Business Ethics, 131(3), 625-648.

Sherman, H. J. (2016). Rise and fall of the Soviet Union. International Journal of Political Economy, 24(1), 5-18.

Sidorsky, D. (2013). Monistic ideals, plural values, and the limits of philosophy. Capitalism \& Society, 8(2), 2.

Talbot, C. (2009). Public value-The next 'big thing' in public management? International Journal of Public Administration, 32(3), 167-170.

Thacher, D., \& Rein, M. (2004). Managing value conflict in public policy. Governance: an International Journal of Policy, Administration, and Institutions, 17(4), 457-486.

UNDP. (2020). Human Development Report 2020. United Nations Development Programme. http://hdr. undp.org/en/content/human-development-index-hdi.

UNEP. (2018). Inclusive Wealth Report 2018. Unite Nations Environment Programme. https://www.unenv ironment.org/resources/report/inclusive-wealth-report-2018.

Wang, B. (2016). Public value in moral market: A case study of human organ transplantation system. International Journal of Public Administration, 39(2), 135-145.

Wang, B., \& Christensen, T. (2017). The open public value account and comprehensive social development: An assessment of China and the United States. Administration \& Society, 49(6), 852-881.

Wang, V. W. (2011). "Chindia" or rivalry? Rising China, rising India, and contending perspectives on IndiaChina relations. Asian Perspective, 35(3), 437-469.

Won, S. Y. (2013). Gender stereotypes toward public-private sphere by gender policy regimes: An international comparison based on WVS. Public Policy Review, 27(4), 5-38.

World Bank. (2020). World Bank Open Data. https://data.worldbank.org/indicator.

Wu, A. M., \& Chou, K. (2021). Intergenerational conflict or solidarity in Hong Kong? A survey of public attitudes toward social spending. Social Indicators Research. https://doi.org/10.1007/ s11205-021-02607-9

Wu, A. M., \& Ramesh, M. (2014). Poverty reduction in urban China: The impact of cash transfers. Social Policy and Society, 13(2), 285-299.

Yue, X. (2008). Party adaptation and the prospects for democratization in authoritarian China. Issues \& Studies, 44(2), 79-102.

Zimmerman, J. M. (2014). Intrinsic vs. extrinsic value. Stanford encyclopedia of philosophy. https://plato. stanford.edu/entries/value-intrinsic-extrinsic/.

Zorba, M. (2009). Conceptualizing Greek cultural policy: The non-democratization of public culture. International Journal of Cultural Policy, 15(3), 245-259.

Publisher's Note Springer Nature remains neutral with regard to jurisdictional claims in published maps and institutional affiliations. 